\title{
GLOBALIZAÇÃO E RECONFIGURAÇÕES DO MERCADO DE TRABALHO EM PORTUGAL E NO BRASIL
}

\section{Adilson Gennari Cristina Albuquerque}

\section{Introdução}

A discussão sobre as reconfiguraçôes atuais do mercado de trabalho, num quadro (aparentemente) hegemônico e globalizado do capitalismo, parece-nos fundamental para a compreensão de novas linhas de recomposição social e, em última instância, para uma discussão crítica sobre as desigualdades socioeconômicas e um novo contrato social. Nesta perspectiva propomo-nos, no presente artigo, a posicionar algumas das mutaçôes em curso no mundo laboral, discutindo seus impactos em termos de precarização do emprego, e apresentar alguns dados que nos permitam ilustrar essas mudanças nos contextos socioeconômicos brasileiro e português.

O pressuposto basilar da nossa argumentação é o de que a sociedade capitalista vem experimentando, nas últimas três décadas, mudanças estruturais

Artigo recebido em 05/11/2010

Aprovado em 20/09/2011 profundas. Tais mudanças decorrem, sobretudo, de três questôes fundamentais: a) o advento da terceira revolução tecnológica (Ianni, 1992; Piore e Sabel, 1984); b) a quase hegemonia do ideário neoliberal na Europa e nos Estados Unidos (Sader, 1995); e c) a derrocada do socialismo real (Kurz, 1992). Com efeito, segundo Anderson (1995), é fundamental ressaltar que a globalização recente do capitalismo implicou, entre outras coisas, a implementação de um conjunto de medidas e de recomendaçôes de política econômica e de política externa, semelhantes em quase todos os países do mundo, e traduzidas no chamado consenso de Washington, ou consenso neoliberal.

Segundo Santos, a globalização, principalmente em seus aspectos econômicos estruturais, possui os seguintes traços fundamentais:

[...] economia dominada pelo sistema financeiro e pelo investimento à escala global; proces- 
sos de produção flexíveis e multilocais; baixos custos de transporte; revolução nas tecnologias de informação e de comunicação; desregulação das economias nacionais; proeminência das agências financeiras multilaterais; emergência de três grandes capitalismos transnacionais: o americano, [...]; o japonês; [...] e o europeu" (2001, p. 35).

Nesse contexto, o crescimento da globalização, sendo em grande medida fruto de mudanças tecnológicas e da introdução de novas tecnologias de informação, tem também contribuído para a precarização e o declínio geral dos sindicatos e para o crescimento do individualismo.

Assim, é notório que as formas de produção sejam definidoras, e decorrentes, do status estrutural da sociedade. No atual quadro da globalização, surgiram as chamadas "corporações de escopo", 1 que procuram extrair mais-valia por meio de novos mecanismos, que incluem a produção de mercadorias para o mercado mundial. É uma organização que tem no aspecto financeiro o seu fundamento nuclear. Refira-se igualmente à tendência para a concentração de tais organizações no setor de serviços. Em acréscimo, a busca permanente de inovações nos produtos e nas formas organizacionais, no quadro da sociedade da informação e da comunicação, é outro aspecto a realçar para a compreensão das metamorfoses em curso no capitalismo e no mundo do trabalho.

Neste quadro analítico, o paradigma do trabalho encontra-se, consequentemente, sujeito a profundas transformações (Wallerstein, 1991; Schnapper, 1998; Sennett, 2001). Estas, associadas às configurações atuais do regime capitalista, tendem a produzir dinâmicas complexas, disseminadas e, geralmente, imprevisíveis, de vulnerabilização das condições de vida dos trabalhadores.

Com efeito, a crise do modelo de produção fordista evidencia-se de forma inequívoca em quase todos os países do mundo, e o desemprego inscreve-se como marca estrutural das sociedades contemporâneas, ${ }^{2}$ obrigando à interrogação sobre a genealogia e a dimensão individual e coletiva dos processos em curso.

A centralidade deste debate decorre, desde logo, da importância assumida pelo trabalho assa- lariado como mecanismo de integração e de reconhecimento social, e mesmo moral, no âmago dos processos de coesão social. Embora muitos analistas políticos e investigadores sociais (Gorz, 1997; Méda, 1999) defendam a tese do "fim do trabalho" como utopia mobilizadora (Habermas, 1985), muitos outros (Castel, 1995; Schnapper, 1998) continuam a advogar a recuperação do sentido do trabalho, ${ }^{3}$ como elemento basilar de cidadania e de participação no "espaço público" (Arendt, 1997). Como evidencia Schnapper, "se hoje devemos repensar o estatuto do trabalho, devemos fazê-lo sem negligenciar este elo original, que continua a ser fundamental, entre o trabalho produtivo e a cidadania. O cidadão moderno adquire a sua dignidade trabalhando" (1998, p. 15).

Com efeito, as sociedades ancoradas no trabalho assalariado constituem-se, desde há três séculos, como o principal meio de subsistência, mas também como elemento constitutivo de relações sociais, na base da cidadania e da construção identitária dos indivíduos.

No âmago da transformação atualmente em curso estaria, porém, o enfraquecimento das funções principais do trabalho (Hespanha et al., 2007; Méda, 1999): a) a produção de bens e serviços, já que com a introdução de novas tecnologias é possível libertar o indivíduo do trabalho produtivo, diminuindo a prevalência do trabalho na vivência pessoal; b) a fonte de emprego e de rendimento, já que o capital tem menos necessidade de recurso a trabalho remunerado, abrindo-se, em paralelo, dimensões menos produtivistas e mais relacionais e comunitárias para o exercício da cidadania; c) a integração social, uma vez que o trabalho, constituindo-se cada vez mais como um bem escasso, tende a potenciar fenômenos de desigualdade, de pobreza e de fragmentação social e identitária.

De fato, não é anódina, como evidencia Méda (1999), a substituição, na retórica política e social das últimas décadas, do conceito de emprego pelo de trabalho. Anuncia-se, desse modo, a emergência de uma sociedade "pós-emprego", na qual os trabalhadores se constituiriam como meros prestadores de serviços, gerindo a respectiva carreira e assumindo, de forma independente, os riscos da incerteza (Hespanha et al., 2007). 
Nessa perspectiva, refletir sobre os fundamentos e as dimensões do trabalho é um ponto de partida incontornável para a determinação dos fins coletivos a efetivar (a "reinvenção da política”, [Beck, 1995]), sobre a relação entre os ditos fins e as opções econômicas e sobre os papéis a desempenhar pelos cidadãos. Em suma, sobre as bases de um (novo) contrato social, reinterpretado à luz dos atuais dados econômicos e políticos em sociedades globais.

Sob tais pressupostos, procuramos, no presente artigo, refletir em torno das (re)configuraçôes do trabalho e do emprego, potenciadas e/ou decorrentes da globalização econômica, nas sociedades portuguesa e brasileira, analisando sobretudo a resignificação, nos contextos atuais, dos processos de precarização do emprego, bem como as evidências ou tendências que esses processos assumem nos dois países em análise.

\section{As metamorfoses do emprego}

A precariedade do emprego, que parece afetar, de forma disseminada, todas as faixas etárias e as categorias profissionais, já não se constitui, nas sociedades contemporâneas, como um mero fenômeno conjuntural. Afirmando-se como eixo central de uma nova configuração econômica e social, a precariedade tende a induzir novos comportamentos e reajustes na relação dos trabalhadores com o mundo do trabalho, com impactos decisivos nos processos de coesão social e na solidariedade de classe.

Com efeito, a globalização tende a gerar ou potenciar, no âmbito dos processos de reorganização econômica, polarizações no mundo do trabalho e do emprego com consequências evidentes e complexas nas dinâmicas de (re)inserção laboral e social de largos extratos da população. Assim, numa das faces da moeda inscrevem-se situações diversas de precariedade que, em última análise, tendem a afetar sobretudo, mas não exclusivamente, os grupos populacionais mais vulneráveis e incapazes de inverter ciclos de precarização, seja devido a um menor domínio da informação e competências pertinentes na sociedade tecnológica, seja na sequência de situações de discrimina- ção, exploração e submissão, como acontece, por exemplo, com os trabalhadores imigrantes. $\mathrm{Na}$ outra face da moeda, novas categorias, qualificadas e adaptáveis, emergem nos interstícios dos fluxos globais. Estas novas "elites socioprofissionais", como são chamadas por Elísio Estanque (2005), dominam as competências necessárias e os fluxos informativos essenciais para a preservação e consolidação do seu poder e influência. Desta forma, como sublinha o mesmo autor (Estanque, 2005), as desigualdades e as distâncias socioespaciais tendem a aumentar no mundo globalizado.

Neste contexto, assiste-se de fato na atualidade, marcada inexoravelmente pelas dinâmicas cruzadas e multifacetadas da globalização, a transformações profundas, quer em termos socioculturais, quer em termos econômicos e laborais. Entre as inúmeras mutaçôes em curso, muitas das quais ainda de contornos imprecisos e questionáveis, a precariedade, no âmago do mercado de trabalho, merece, pela relevância que possui nos dois contextos que ilustram a nossa reflexão, um maior realce.

Segundo Kalleberg, "o trabalho precário nas últimas décadas é o resultado do crescimento da globalização - interdependência econômica e seus correlatos, tais como maior comércio internacional e movimento acelerado de capital, produção e trabalho - e da expansão do neoliberalismo (uma ideologia que implica desregulação, privatização e remoção de proteções sociais)" (2009, p. 22).

A precisão do conceito de precarização pressupõe, na nossa ótica, a consideração de duas dimensões: uma dimensão comparativa - algo é precário, assumindo diversas gradações, por referência a algo com contornos mais estáveis - e uma dimensão valorativa, associada à imprevisibilidade, fragilidade e deterioração. Nesse âmbito, o conceito em tela consagra a ideia de que o paradigma do emprego permanente (para toda a vida ativa), homogêneo e previsível, predominante sensivelmente até as décadas de 1970 e 1980 (Castel, 1995), se transforma hoje em profundidade e de modo perene. Além disso, traduz uma concepção de perda de qualidade do trabalho, de insegurança e de deterioração das relações laborais, que acaba por ter impactos também nas relações sociais e na identidade dos indivíduos. 
As configurações do mercado de trabalho e as mutaçôes nos modelos organizativos e nos vínculos laborais, associadas, por exemplo, à flexibilização, aos contratos a prazo, à prestação de serviços etc., bem como legislaçôes laborais mais permissivas, permitindo ao empregador, por exemplo, maior facilidade de demissão ou de redução salarial e a orientação para a desregulação do mercado de trabalho, consubstanciam a dimensão estrutural da precarização. Esta acaba por traduzir-se em formas de trabalho precário, já não esporádicas e periféricas, mas cada vez mais estratégicas e centrais na própria lógica de dominação capitalista atual (Leite, 2009, p.14).

A compreensão do conceito de trabalho precário, ${ }^{4}$ que não é verdadeiramente novo mas que adquire hoje novos sentidos e amplitudes, pressupõe, como sublinham Janice e Gery Rodgers (1989, p. 3), a identificação e a avaliação não apenas das respectivas dimensões - grau de instabilidade; grau de controle dos trabalhadores sobre as condições de trabalho, nomeadamente em relação ao salário, à gestão de tempo de trabalho e de tempo livre, entre outras; proteção, quer por via de legislação laboral, quer de contratos coletivos de trabalho e rendimento -, mas igualmente, e sobretudo, das formas complexas como tais dimensões se combinam, de suas causas e efeitos.

Diversos autores apontam a fragmentação do mercado de trabalho - entre um núcleo produtivo, com assalariados a tempo integral e maiores perspectivas de progressão, e uma massa de trabalhadores com enquadramentos precários - como o elemento estruturante do mundo laboral moderno. No entanto, esta tese é, no entender de Janice e Gery Rodgers, discutível nos contextos atuais. Falar de um mercado dual, dicotomizando precários e não precários, parece inadequado a partir do momento em que certas formas de trabalho precário coexistem com modelos mais estáveis na mesma empresa ou serviço. A realidade é, pois, cada vez mais complexa e menos delimitada.

Novos modelos de trabalho, de cariz híbrido, tendem a adquirir cada vez mais centralidade no contexto da terceirização das empresas, processo fortemente impulsionado pela globalização. Surgem assim empresas de prestação de serviços com trabalhadores permanentes, empresas de subcontratação com trabalhadores temporários ou agências de trabalho temporal com trabalhadores em grande rotatividade (Caire, 1982). Estes modelos encontram-se bem presentes, quer em Portugal, quer no Brasil. Os jovens (sobretudo qualificados) que em Portugal desempenham, como prestadores de serviços, funções permanentes; os operadores de call centers e de marketing (em grande número jovens estudantes) que, nos dois países, são sujeitos a padrões exigentes de controle, de produtividade e de rotatividade; os trabalhadores em regime de subcontratação com direitos e capacidade reivindicativa reduzidos ante a diluição da visibilidade e das responsabilidades do "empregador real”, entre outros, são exemplos paradigmáticos dos novos modos de estruturação do emprego nos dois contextos.

No estudo coordenado por Rosa (2000), sobre trabalho precário em Portugal, são identificadas oito formas desse tipo de trabalho: a tempo parcial involuntário; com contrato a termo; temporário; falsos trabalhadores por conta própria; sazonal; ocasional; no domicílio; em regime de subempreitada. ${ }^{5}$ A subcontratação, por exemplo, associa-se a uma lógica de lean production, com a criação de pequenas empresas e de fornecedores, nas quais o trabalho não tem a mesma proteção, nem o mesmo estatuto que possui na empresa núcleo.

No contexto brasileiro, os tipos de trabalho precário formam um leque extraordinário com uma profusão de atividades, dentre as quais destacaríamos os trabalhadores com atividades assalariadas, por tarefa e os autônomos. São, por exemplo, trabalhadores part time e com contrato temporário; trabalhadores ilegais, como por exemplo, imigrantes de outros países latino-americanos, como a Bolívia e o Peru, que trabalham nas pequenas indústrias têxteis clandestinas no município de São Paulo; todo um conjunto de trabalhadores domésticos sem registro em carteira e sem proteção; empregadas domésticas sem registro; faxineiras diaristas; trabalhadores agrícolas em atividades sazonais, como por exemplo no corte de cana-de-açúcar. Há também trabalhadores terceirizados, como porteiros, faxineiros, jardineiros, seguranças de patrimônio público, copeiras etc. 
Efetivamente, nas últimas duas décadas sobretudo, como referenciam Beaud e Pialoux, tende a diluir-se a figura do "trabalhador" ou do "operário" (apoiado por um sentido de classe), surgindo em seu lugar a figura do "'assalariado da precariedade” (Paugam), do operador, do operário flexível e utilizado segundo as conveniências de cada momento, reduzido à sua condição de operário intercambiável, sem consciência de si” (apud Leite, 2009, p. 18).

$\mathrm{Na}$ verdade, sob o imperativo da flexibilidade, num contexto de concorrência global e de mundialização do capital, evidencia-se a chamada "subproletarização tardia”, eufemisticamente associada por alguns a uma lógica de informalização das relações laborais. Deste subproletariado tardio fariam parte dois subgrupos: a) o dos assalariados com competências menos especializadas, facilmente disponíveis no mercado de trabalho e, por isso, com taxas elevadas de rotatividade e menos oportunidades de progressão na carreira; b) o dos trabalhadores com vínculos laborais precários.

Nesse contexto, os processos de flexibilização do trabalho, em termos contratuais, espaciais ou estatutários (Beck, 1992; Castells, 1999), pretensamente associados a padróes atuais de maior dinamismo e competitividade econômica, não deixam de potenciar igualmente formas de precarização do emprego e de dissolução de um horizonte de futuro, paradoxalmente essencial à própria dinâmica econômica. Enfatizando a mesma ideia, Hespanha afirma que

[...] no quadro da economia globalizada, comandada pela lógica financeira da rentabilidade no curto prazo, legitimada pelas políticas neoliberais e fortemente apoiada nas inovaçōes tecnológicas, é crescente a pressão para flexibilizar continuamente o fator trabalho. Dele se exige resposta rápida, fácil e a baixo custo às variaçôes do mercado. Neste quadro, o trabalho deixou de ser entendido como um direito e tornou-se um mero recurso ao serviço da competitividade das empresas (2007, p. 21).

Em paralelo, evidenciam-se, ao menos aparentemente, duas tendências de sinais contrários nos novos modos de estruturação do emprego: uma no sentido do incremento do trabalho informal; outra na linha de uma maior "racionalização" do trabalho (Ritzer, 1996).

No que diz respeito à primeira, diversos estudos e dados empíricos vêm demonstrando que a informalidade, ${ }^{6}$ contrariamente ao que se esperava há quatro décadas atrás (Tokman, 2004; Leite, 2009), cresceu nas sociedades capitalistas globalizadas e adquiriu mesmo novas configuraçôes. A chamada "nova informalidade" (Baltar e Deddeca, 1997; Noronha, 2003), emerge e ganha sentido nos interstícios da própria formalidade. "Assalariados disfarçados" (Portes, Castells e Benton, 1989) constituem, sob este prisma, o "excedente de mão de obra que está disponível para responder às necessidades dos setores mais modernos, permitindo diminuir os custos de trabalho" (Tokman, 2004, p. 200).

A segunda tendência remete-nos para a prevalência da eficiência, da previsibilidade, da calculabilidade, da "tecnologia humana" e do controle sobre a incerteza, que George Ritzer (1996) agrega sob a noção de "McDonaldization". ${ }^{7} \mathrm{O}$ conceito pretende traduzir a ideia de um processo de racionalização (e de consequente irracionalização) que é disseminado, numa lógica "mecânica" e "alienante" (por via de técnicas, procedimentos, rotinas, controle, rapidez, eficiência etc.), dos contextos laborais aos processos de interação e às identidades.

Numa perspectiva complementar, Scott Lash (1995) associa o mesmo conceito à ideia de domínio ou de não domínio da informação e dos conhecimentos pertinentes para a integração social e laboral, tornando-se por essa via facilmente "descartável" e invisível.

Com efeito, na globalização, num contexto de "modernização reflexiva" (Beck, Giddens e Lash, 1995), a acumulação de capital é simultaneamente acumulação de informação. Há uma profunda mutação nas classes sociais. A classe trabalhadora, na chamada modernidade reflexiva, trabalha dentro de estruturas de informação e comunicação de três formas: como consumidora, como utilizadora de meios informatizados e como produtora de bens de consumo (Lash, 1995). Assim, para Lash, na atual "sociedade reflexiva", há um conjunto de "ganhadores" e outro de "perdedores". Estes, na realidade, caracterizam-se por sua exclusão sistemática das 
estruturas de informação e comunicação. O novo "proletariado McDonald's", como é chamado pelo autor, é, assim, composto pelos pobres, que via de regra residem em guetos urbanos, sobretudo em guetos simbólicos e excludentes, perversa e continuamente (auto)reproduzidos.

A dimensão do conhecimento, mais ou menos especializado ou transversal, das competências, sobretudo tecnológicas e de gestão, e da informação torna-se, efetivamente, um elemento basilar para a compreensão das sociedades atuais e, em consequência, um fator estruturante para a compreensão das dinâmicas contemporâneas dos mercados de trabalho em escala global.

A globalização tem implicado, de fato, como evidenciam alguns autores, a substituição da "economia do trabalho" pela "economia do conhecimento" (knowledge based economy), como mecanismo renovado de acumulação de capital, apostando em processos de investigação e desenvolvimento, (re)qualificação dos recursos humanos ao longo da vida, consultorias, estudos de mercado e de níveis de satisfação, entre outros aspectos. Nesse contexto, a nova categoria do que poderíamos nomear de "trabalhadores do conhecimento" redimensiona o conceito de "autogestão dos trabalhadores", considerada doravante como autogestão do conhecimento e da aprendizagem, quer numa dimensão individual, quer coletiva ou organizacional (Murteira, 2004, p. 16). Isto significa que os próprios trabalhadores, incentivados ou impulsionados pela estratégia das organizações ou empresas, constroem e reconstroem em continuidade a sua própria formação e conhecimento no sentido de incrementar a capacidade de organizar a informação que está ao seu dispor (codificada ou não), ou que aprendem a identificar e valorizar, para responder de forma cada vez mais proficiente às questôes complexas e imprevisíveis do mundo do trabalho no contexto global. Na chamada "economia baseada no conhecimento", "os conhecimentos essenciais para os mercados globalizados transformam-se assim em mercadorias, em autênticos 'pacotes' que só nestes mercados possuem eficácia e valor de troca” (Idem, p. 11).

Nesse contexto, verifica-se uma metamorfose significativa das configurações da força de trabalho, uma verdadeira mutação da classe trabalhadora global. Vários são os aspectos dessa mudança, dentre os quais merecem atenção duas tendências: a polarização, com contornos inéditos, entre trabalho qualificado e não qualificado (Reich, 2001; Sklair, 1991), e a exigência acrescida de especialização e de transversalidade combinadas, conduzindo à transposição do conceito de trabalhador qualificado para o de "trabalhador complexo".

As organizações privadas, públicas ou autárquicas, principalmente nos setores de serviços, demandam efetivamente um novo tipo de trabalhador, que deve possuir uma profunda formação específica e, ao mesmo tempo, uma formação geral bastante abrangente, bem como competências associadas à capacidade adaptativa - flexibilidade e mobilidade -, podendo operar em vários ramos e setores da atividade econômica. São assim solicitados trabalhadores com este novo perfil em várias organizações globais e, de forma concomitante, assiste-se à demissão e à transformação de "exércitos de trabalhadores" em seres "supérfluos", como na tese clássica da teoria da população de Karl Marx (1980).

Este elemento, central para a compreensão dos mecanismos da divisão social do trabalho na atualidade, constitui-se como um novo cenário de gestão estratégica do capital diante da imprevisibilidade dos mercados, comportando, porém, riscos acrescidos de fragmentação social. A possibilidade de dispensar trabalhadores, sem maiores custos diretos, sempre que as lógicas do mercado assim o determinem, transforma as pessoas em meras peças de uma engrenagem econômica que parece cada vez mais impor-se per si. O mercado de trabalho atual assenta-se, pois, num paradoxo inédito e propiciador do incremento das desigualdades socioeconômicas: a afirmação da precariedade como argumento e fator de preservação desse mesmo mercado.

Os níveis de desemprego, a sua duração e o perfil dos desempregados são igualmente, nesse contexto, um fator relevante a considerar numa ótica de ponderação da dinâmica dos mercados e da sua capacidade ou incapacidade para gerar novos empregos e responder aos desafios inerentes à competitividade econômica em escala global. Portugal e Brasil encontram-se nesse sentido, como vamos ver, em rotas diferenciadas. 
Tais mutações ocorrem em paralelo com a avassaladora dominação cultural e ideológica por parte das personas do capital. Com a crise do Leste Europeu e das esquerdas, disseminou-se, por todos os continentes (embora com diferenças significativas), a ideologia liberal e neoliberal. Nesse quadro, os dogmas relacionados com o individualismo, a competição e a concorrência instalaram-se como padrôes vivenciais e axiológicos, propiciadores de uma lógica consumista e determinantes na afirmação de padrões comparativos e na construção de interações, ${ }^{8}$ quer em contextos de proximidade, quer em contextos supralocais ou supranacionais.

\section{(Re)Configurações do emprego}

No quadro que brevemente referenciamos, verifica-se uma elevação sem precedentes dos níveis de desemprego (e da respectiva duração) e de informalização do trabalho por todo o mundo industrializado. Com efeito, as forças racionalizadoras, liberadas pela chamada terceira revolução industrial, são hoje mais intensas do que as forças geradoras de emprego.

Os dados para a América Latina são enfáticos nesse sentido. Se em 1990 a taxa de desemprego era de 6,2\%, em 2009 atingia 8,3\% (Cepal, 2009). Além disso, as mudanças não foram apenas quantitativas, mas também qualitativas. Segundo o Relatório da Cepal,

[...] o processo de globalização e de transformação produtiva em curso há algumas décadas não só implicou uma reorganização profunda dos sistemas produtivos, da estrutura ocupacional e dos mercados de trabalho à escala mundial, mas também apresentou novos e importantes desafios para a investigação e para o desenho de políticas no âmbito do emprego (2007, p. 130).

Do mesmo modo, o Relatório da OIT sobre as Tendências Mundiais do Emprego (2009) destaca o aumento da taxa de desemprego na América Latina e no Caribe para 8,2\% em 2009 contra $7 \%$ em 2008, o que corresponde a um aumento de cerca de 4 milhões de desempregados. O mesmo Relatório sublinha ainda o aumento do número de trabalhadores em situação de pobreza extrema, de 7\% em 2008 para 9,9\% em 2009.

Também no contexto da União Europeia (UE), verifica-se, nas últimas duas décadas, de acordo com dados do Eurostat (2010a), um incremento do desemprego, correspondendo atualmente a uma taxa de cerca de $9,6 \%$ da população europeia em idade ativa, contra $6 \%$ em 2008 , data de início da crise econômico-financeira global (o que corresponde a um aumento de cerca de 12 milhões de pessoas só em 2009). O desemprego na UE corresponde assim, desde 2007, a mais de 40\% do desemprego global (OIT, 2009).

Nas conferências europeias de Luxemburgo (1987) e de Lisboa (2000), foram identificados os fatores que delineiam a situação do emprego no contexto da União, cuja atualidade continua a verificar-se e de modo ainda mais evidente no presente contexto de crise: baixa taxa de oferta de emprego a par de um grande número de desempregados e da persistência do desemprego crônico; agravamento das assimetrias regionais no mercado de trabalho e o incremento da precarização dos vínculos sociolaborais, e o incremento da dificuldade no acesso ao emprego, sobretudo para populações com características específicas, em função das habilitações, da idade ou do sexo.

Esta situação é atualmente tanto mais grave quanto mais a União se confronta com a necessidade de equilíbrio das finanças públicas e a necessidade de controle do déficit em países como Portugal, Espanha, Irlanda e Grécia, obrigando a uma restrição 9 dos apoios sociais e à consequente centralidade em mecanismos de governabilidade e de estabilização financeira, na senda da chamada Estratégia de Lisboa (2005).

O "regresso ao trabalho" tem sido, no entanto, invocado como o eixo central para a inclusão social e para a manutenção e a renovação do modelo social europeu. Assim, no quadro de uma estratégia global de combate à desqualificação e à pobreza, a UE tem promovido novas formas de regulação socioeconômica (Programas Nacionais de Reforma) pela via da articulação entre políticas econômicas, sociais e de emprego (patentes desde a Conferência 
de Nice, em 2000, até a Estratégia Europa 2020) e pelo apelo à maior implicação dos indivíduos e da sociedade civil na ativação de respostas inovadoras para problemas estruturais.

No Brasil, com o propósito alternativo de combater a informalidade e promover a "inclusão", houve a iniciativa de constituição, no âmbito do Ministério do Trabalho, da Secretaria Nacional de Economia Solidária - Senaes, sob a coordenação do economista Paul Israel Singer. Não faz parte dos propósitos deste artigo abarcar os debates políticos e teóricos sobre a chamada economia solidária, apenas cabe indicar que, paradoxalmente, ali encontram-se tanto características do próprio processo de flexibilização do trabalho no Brasil, como de alternativas reais para os trabalhadores de baixa renda (Benini, 2011).

Em termos mais específicos, quer Portugal, quer o Brasil, salvaguardadas as diferenças de escala, se confrontam hoje com problemas profundos associados à dualização socioeconômica das respectivas sociedades e à necessidade de ponderar mecanismos eficazes de harmonia entre crescimento econômico, emprego e equidade social.

\section{Desemprego e precarização do trabalho em Portugal}

De acordo com o European Restructuring Monitor, entidade que tem como função monitorizar o processo de criação ou supressão de emprego por parte das empresas, Portugal é um dos países da União Europeia mais afetado pelas dinâmicas de deslocalização para os países do ex-Bloco de Les- te (particularmente, República Checa, Hungria e Eslováquia). A este respeito, diversos economistas apontam a elevada carga fiscal em Portugal, a que acresce uma massa de trabalhadores, na sua maioria pouco qualificados, como fatores explicativos para a saída das empresas do contexto português. Com efeito, em Portugal, como se evidencia no estudo $E$ o desemprego fonte de pobreza?

[...] muitas empresas localizaram-se, outras reestruturaram-se, outras, sujeitas à competição externa, revelaram-se incapazes de sobreviver neste quadro, devido às suas debilidades estruturais. As consequências são óbvias e muito mediatizadas: vagas de despedimento que engrossam os números do desemprego. Para além do desemprego, as mudanças verificadas provocaram também uma forte tendência para a precarização do trabalho e para a desregulamentação e flexibilização das condições em que ele é desenvolvido (Hespanha et al., 2007, p. 42).

No que concerne ao primeiro aspecto referenciado, o desemprego, Portugal possui hoje, de acordo com os últimos dados divulgados pelo Instituto Nacional de Estatística, referentes ao primeiro trimestre de 2011, uma taxa oficial de desemprego de $12,4 \%$ (correspondendo a cerca de 688,9 mil portugueses sem trabalho, dos quais 126 mil são jovens), ${ }^{10}$ a mais alta da sua história e a quarta mais elevada entre 21 países da UE com informação apurada para o período em referência (Eurostat, 2011). Uma comparação dos valores da última década (Tabela 1) permite-nos concluir que em 2010

Tabela 1

Taxa de Desemprego da População Portuguesa em Comparação com a União Europeia a 27 Países

\begin{tabular}{llllllllllll}
\hline Ano & $\mathbf{2 0 0 1}$ & $\mathbf{2 0 0 2}$ & $\mathbf{2 0 0 3}$ & $\mathbf{2 0 0 4}$ & $\mathbf{2 0 0 5}$ & $\mathbf{2 0 0 6}$ & $\mathbf{2 0 0 7}$ & $\mathbf{2 0 0 8}$ & $\mathbf{2 0 0 9}$ & $\begin{array}{l}\mathbf{2 0 1 0} \\
\text { dez. }\end{array}$ & $\begin{array}{l}\mathbf{2 0 1 1} \\
\text { abril }\end{array}$ \\
\hline $\begin{array}{l}\text { Taxa de } \\
\text { desemprego em } \\
\text { Portugal }\end{array}$ & 4,1 & 5,1 & 6,4 & 6,7 & 7,7 & 7,8 & 8,1 & 7,7 & 9,6 & 11,2 & 12,6 \\
\hline $\begin{array}{l}\text { Taxa de } \\
\text { desemprego na UE }\end{array}$ & 8,5 & 8,9 & 9,0 & 9,1 & 8,9 & 8,2 & 7,1 & 7,0 & 8,9 & 9,5 & 9,4 \\
\hline
\end{tabular}

Fonte: Eurostat (2010b, 2011). 
Tabela 2

Evolução dos Contratos com Duração Determinada em Portugal (\% do emprego total) em Comparação com a União Europeia

\begin{tabular}{lllllllllll}
\hline Ano & $\mathbf{2 0 0 1}$ & $\mathbf{2 0 0 2}$ & $\mathbf{2 0 0 3}$ & $\mathbf{2 0 0 4}$ & $\mathbf{2 0 0 5}$ & $\mathbf{2 0 0 6}$ & $\mathbf{2 0 0 7}$ & $\mathbf{2 0 0 8}$ & $\mathbf{2 0 0 9}$ & $\mathbf{2 0 1 0}$ \\
\hline Portugal & 20,3 & 21,5 & 20,6 & 19,8 & 19,5 & 20,6 & 22,4 & 22,8 & 22,0 & 23,0 \\
\hline EU (27) & 12,4 & 12,3 & 12,7 & 13,3 & 14,0 & 14,5 & 14,6 & 14,2 & 13,6 & 14,0 \\
\hline
\end{tabular}

Fonte: Eurostat (2011).

a taxa de desemprego $(11,2 \%)$ corresponde a mais do dobro da verificada em 2001 (4,1\%), sendo que nos últimos quatro anos esta taxa se situa acima da taxa média da UE.

O desemprego é inequivocamente um dos problemas mais graves da atual situação socioeconômica do país, sobretudo devido à tendência ascendente que tem assumido, às populações cada vez mais heterogêneas que atinge, ao aumento das situaçôes de desemprego de longa e de muito longa duração ${ }^{11}$ e às dificuldades estruturais do país de recuperação econômica e de resposta adequada aos fluxos e às pressões globais.

A estagnação da economia e o cada vez maior distanciamento dos ritmos de crescimento e desenvolvimento da União Europeia; o aumento já referido do desemprego nas últimas décadas; os baixos salários; um tecido empresarial pouco competitivo e resistente à inovação e investigação; um déficit das contas públicas que atingiu em 2010, de acordo com os dados do Instituto Nacional de Estatística (INE, 2010), a cifra de $9,1 \%,{ }^{12}$ a par do fortíssimo endividamento das empresas e do país ao exterior (com os juros da dívida soberana a 10 anos a atingirem, em junho de 2011, o valor histórico de $10,3 \%)$, todos esses fatores caracterizam Portugal como um país em grave crise socioeconômica e de enorme vulnerabilidade em face do exterior.

A entrada de Portugal na UE, em 1986, significou de fato transformaçóes nas formas tradicionais de regulação social, econômica, política e cultural (Santos, 2001; Hespanha e Carapinheiro, 2001), mas revelou também as fragilidades estruturais do país para responder aos desafios da competitividade econômica e o seu afastamento progressivo e acentuado das metas de desenvolvimento e de coesão econômica e social.

Também os níveis de precariedade do emprego, embora com muitas flutuações, tendem a constituir-se como uma dimensão relevante para a compreensão do tecido socioeconômico português. De acordo com os dados mais recentes divulgados pelo Eurostat (Tabela 2), Portugal é o terceiro país da União Europeia (depois de Polônia e Espanha) com maior nível de precariedade. Se considerarmos um dos critérios associados à definição de trabalho precário, o emprego temporário, ${ }^{13}$ podemos falar da proporção de um em cada cinco empregados nesta situação.

Dados de 2010 revelam também que se intensificou o número de trabalhadores, sobretudo jovens, ${ }^{14}$ que exercem funções (muitas vezes de cariz central e estratégico) em regime de "trabalho independente" (os "falsos assalariados" a que já nos referimos).

Esses fatores, em paralelo com uma economia informal forte e largamente inapreensível, com a exploração de uma enorme massa de imigrantes sem documentação (sobretudo provenientes do Brasil e dos países do Leste Europeu), com um contingente significativo de trabalhadores pauperizados ${ }^{15}$ por baixíssimos salários (mesmo entre a população qualificada com formação superior, a chamada "geração PREC" ou "geração 500", por auferir salários de cerca de 500 euros/mês) e com situações de "nova escravatura" e tráfico de mão de obra (imigrante e emigrante), resultam como reconfigurações do emprego, geradas e/ou potenciadas pela globalização, e que tendem a conduzir e a enquadrar em novas situações de pobreza setores populacionais heterogêneos e vulnerabilizados (Estanque, 2005). 


\section{Desemprego e precarização do trabalho no Brasil}

O chamado mundo do trabalho ganhou uma nova configuração, principalmente com a ascensão ao poder do presidente Fernando Collor de Melo em 1990. Entretanto, num momento imediatamente anterior é preciso considerar todas as indicaçôes de mudanças, principalmente no âmbito social, referidas na nova Constituição de 1988. Outro fator muito relevante foi, sem dúvida, o início do processo de abertura econômica do programa do governo Collor de Melo.

As políticas de cunho neoliberal, principalmente no que tange à abertura econômica, à flexibilização da estrutura econômica e social e à prática de altas taxas de juros, exerceram pressōes consideráveis no nível e no perfil do emprego. O resultado evidente foi uma reestruturação do mercado de trabalho e o incremento do desemprego. Essas transformações associadas ao crescente processo de introdução de inovações tecnológicas, reestruturação industrial, terceirização dos serviços, flexibilização produtiva etc. exerceram pressões que introduziram uma profunda alteração na estrutura econômica capitalista, cujo epicentro está mais no aumento da velocidade de rotação do capital, acompanhado de maior racionalização, do que na geração de novos empregos. $\mathrm{O}$ resultado tem sido uma mudança no perfil do emprego ou, dito de outro modo, fragmentação, informalização, terceirização, trabalho part time etc., ou seja, a precarização do emprego.

Nesse sentido, ao tecer uma análise comparativa sobre as transformaçōes no mundo do trabalho no Brasil e na Europa, Nadya Guimarães entende que as análises comparativas se mostram interessantes, uma vez que ambas as realidades vêm sofrendo as mesmas pressóes do processo de globalização. Entretanto, ela assegura que o Brasil tem sua especificidade e diferencial graças à dificuldade de delimitação das fronteiras entre atividade e inatividade, pelo que o "o desemprego recorrente assume, no Brasil, características diferentes, podendo ser interpretado como um fenômeno especial, algo distinto do esperado aos observadores atentos à realidade" (Guimarãres, 2004, p. 22). As diferenças entre a experiência brasileira e a da Europa ocidental estão radicadas sobretudo na natureza dos fenômenos. Como afirma a autora,
[...] no Brasil, [o desemprego] não somente afeta uma parcela maior da força de trabalho, mas ele implica em transições que levam o trabalhador a adentrar e ausentar-se, reiteradamente, do próprio mercado de trabalho, o que põe em xeque não apenas a natureza e características do fenômeno do desemprego, mas a natureza e características do fenômeno da inatividade" (Idem, ibidem).

Por outro lado, as semelhanças, identificadas pela autora, por referência a países como a França, baseiam-se nos "intensos movimentos de entrada e saída (de curto prazo) do desemprego" (Idem, ibidem).

Embora a recorrência do desemprego e as "ausências" do mercado de trabalho, por via nomeadamente da economia informal, sejam aspectos partilhados com o contexto português, em Portugal não se verifica a mesma plasticidade do mercado de trabalho, permitindo processos de transiçãoo relativamente rápida e contínua do emprego ao desemprego e vice-versa. Do mesmo modo, as formas de gerir o período de inatividade, por via de estratégias de autossustentabilidade e de empreendedorismo, são (até pela debilidade dos apoios públicos no período de desemprego) muito mais evidentes na sociedade brasileira.

Com efeito, no Brasil, diferentemente dos países europeus, a institucionalização do desemprego é tanto recente como limitada. Segundo Guimarães,

[...] em um contexto de forte diminuição dos empregos formalmente registrados e protegidos, notável sobretudo no setor industrial no decurso dos anos de 1990, as atividades ocupacionais não registradas (como a dos assalariados sem registro em carteira e dos trabalhadores por conta própria) asseguraram o essencial da flexibilidade do emprego (representando mais da metade dos empregos), e alimentando, ao mesmo tempo, o crescimento das atividades de serviços e dos "bicos" (Idem, p. 24).

O Brasil possui efetivamente um sistema recente, sendo o mais importante o seguro desemprego, instituído em 1986, que garante o direito ao desempregado de receber até cinco parcelas de 
Tabela 4

Evolução da Taxa de Desemprego no Brasil

\begin{tabular}{llllllllll}
\hline Ano & $\mathbf{2 0 0 2}$ & $\mathbf{2 0 0 3}$ & $\mathbf{2 0 0 4}$ & $\mathbf{2 0 0 5}$ & $\mathbf{2 0 0 6}$ & $\mathbf{2 0 0 7}$ & $\mathbf{2 0 0 8}$ & $\mathbf{2 0 0 9}$ & $\mathbf{2 0 1 0}$ \\
\hline Taxa de desemprego & 12,6 & 12,3 & 11,4 & 9,8 & 9,9 & 9,3 & 7,8 & 8,1 & 6,7 \\
\hline
\end{tabular}

Fonte: Instituto Brasileiro de Geografia e Estatística (www.ibge.gov.br, PME) (acesso em 12/6/2011).

um benefício equivalente à média dos últimos três salários recebidos, desde que comprove ter tido emprego nos últimos seis meses consecutivos imediatamente anteriores ao desemprego. Existe ainda um benefício oferecido ao pescador artesanal e também ao trabalhador resgatado de trabalho considerado forçado ou com características de trabalho escravo.

De forma mais precisa, os dados sobre a variação do emprego no Brasil são significativos. As taxas de desemprego atuais apresentadas pelas pesquisas do Dieese para as grandes capitais atingem cerca de 10\% (Dieese, 2010). Verifica-se, ainda assim, de acordo com os dados da última década divulgados pelo IBGE (Tabela 4), uma tendência de diminuição (com exceção para o ano 2009) progressiva das taxas de desemprego no Brasil.

A par deste movimento positivo de variação do desemprego, verifica-se também uma tendência significativa de criação de empregos. Segundo os dados apresentados pelo Ministério do Trabalho do Brasil, "o número total de empregos formais registrados no Brasil alcançou 44,1 milhões em dezembro de 2010, representando um crescimento de $6,94 \%$ em relação ao estoque de emprego de dezembro de 2009. Esse desempenho equivaleu ao acréscimo de 2,9 milhōes de postos de trabalho formais em relação ao mesmo mês do ano anterior". ${ }^{16}$ Os dados mais recentes sobre a realidade brasileira, disponíveis no Ipeadata, demonstram igualmente uma ligeira queda nos níveis de informalidade nos anos entre 2003 e 2007. Ainda assim, na virada do milênio os dados do IBGE $^{17}$ demonstram que $56 \%$ dos trabalhadores estavam na informalidade. Segundos os mesmos dados, no início da primeira década a tendência se manteve, sendo a taxa de informalidade em 2001 de 55,2\% e, em 2002, de $55,3 \%$. Entretanto, a partir de 2003 os dados demonstram uma pequena mas constante melhora que está de acordo ou em paralelo com outros indicadores macroeconômicos do período, sendo que as taxas de 2004 a 2008 foram respectivamente $53,8 \%, 53,1 \%, 52,1 \%$. 50,8\%. 49,2\%, chegando em 2009, último dado disponível, à 48,7\%. Embora tais dados não nos permitam concluir que a diminuição da informalidade se traduz necessariamente numa maior qualidade do emprego (aspecto a explorar em estudos mais profundos e qualitativos), traduz inequivocamente a minimização de algumas situaçōes de invisibilidade e de ausências de um estatuto de cidadania que a informalidade por definição enquadra e perpetua.

A precariedade do trabalho no Brasil está, pois, bastante associada ao trabalho na chamada economia informal (atividades que são desenvolvidas sem, ou à margem, de toda regulamentação advinda do Estado), apesar das tendências de melhora que já sublinhamos. Também em Portugal esta questão se coloca acrescendo a enorme panóplia de situações de trabalhos com duração limitada.

\section{Consideraçóes finais}

A globalização do capitalismo é fruto e motor de grandes transformaçôes tecnológicas e inovaçōes, notadamente nas áreas de informática e comunicação. Essas mudanças não são neutras tampouco automaticamente determinadas pelas estruturas econômicas. São, sobretudo, derivadas de decisões de política socioeconômica definidas na arena política.

Esta análise evidenciou que a flexibilização e a desregulação produtiva atinge em cheio o chamado mundo do trabalho e, diretamente, a configuração da classe trabalhadora. Por exemplo, na mudança do perfil do mercado de trabalho. A ampliação da precarização se mostra significativa e fruto da fragmentação das relações laborais, cujo subproduto aparece como trabalho part time, por tarefa, tercei- 
rizado, doméstico e todas as formas de "viração" ou de "biscate". O desemprego também muda de perfil, e parte expressiva dele se transforma em desemprego de longa duração. Além disso, a hibridização de novas e velhas formas de trabalho atípico e as osmoses complexas entre trabalho formal e informal, patentes quer no Brasil, quer em Portugal, constituem-se, na nossa perspectiva, um dado muito relevante para compreender as sociedades em análise, os desafios com que se confrontam e as fraturas sociais, que sob o prisma da injustiça, da desigualdade e de proteções associadas podem aumentar e eclodir.

As pressões e as tendências que, neste domínio, se a Portugal e ao Brasil são idênticas, ainda que com impactos diferenciados em virtude das tendências de sinal oposto em termos de crescimento que caracterizam as duas economias na atualidade. As mudanças em pauta evidenciam, assim, uma dimensão estrutural do fenômeno e configuram uma nova forma de estruturação do trabalho e do emprego no capitalismo globalizado. Entretanto, aprofundam-se ou complexificam-se as mazelas sociais, em Portugal com a grave crise econômica e social que atravessa, no Brasil com novos precários sobretudo no contexto urbano e fruto da maior sofisticação do emprego. Emerge por isso a necessidade de aprofundamento do debate sobre a necessidade da "reinvenção da política" (Beck, 1995), da retomada da agenda do desenvolvimento com equidade social e uma criteriosa avaliação multidisciplinar do novo contexto civilizacional.

O enfraquecimento da função integradora do trabalho nos coloca igualmente questões de relevo no que concerne aos padrões de coesão social e econômica e à reinterpretação da cidadania social, mesmo em contextos com economias emergentes como é o caso do Brasil. Os indicadores de recuperação econômica e de melhora nas taxas (patente estatisticamente em ambos os países) de pobreza e nos índices de desigualdade ao longo da última década não nos isenta de uma reflexão sobre as efetivas condiçôes de vida das populaçôes e sobre a qualidade do emprego.

O neopauperismo, associado sobretudo aos baixos salários, e a precarização das relaçōes sociais e laborais colocam, de fato, em primeira linha, não somente os desafios, para os sistemas de pro- teção social, associados às possibilidades de manutenção de direitos e de pressupostos de dignidade para verdadeiros exércitos de desempregados sobre numerários, com perfis heterogêneos e aleatórios, e de working poors, mas também as bases do auto e hétero reconhecimento. Neste contexto, a necessária "reinvenção da política" deve permitir uma abordagem crítica das alternativas sem hipotecar os fundamentos do bem-estar coletivo e da dignidade humana nas sociedades complexas e globais da atualidade.

\section{Notas}

1 Esta expressão foi criada por José Carlos Braga (1997) e conceitualiza uma nova corporação, com novas características: são produtoras de mercadorias para o mercado mundial, produzidas com alta composição tecnológica; além disso a produção está fortemente associada ao capital financeiro, como função da composição de seus lucros.

2 O Relatório da OIT sobre Tendências Mundiais do Emprego (2009) identifica 212 milhōes de desempregados no mundo (mais 34 milhōes de pessoas por referência a 2007 antes da crise global), destacando o aumento previsível de 3 milhōes de desempregados, só no contexto da União Europeia (UE), no ano de 2010.

3 Destacado igualmente nas Conferências Europeias do Luxemburgo (1997) e de Lisboa (2000) e, mais recentemente (2009), no Pacto Mundial para o Emprego da OIT (2009). Pacto este decorrente da Decent Work Agenda no âmbito da "Declaration on social justice for a fair globalization" (OIT, 2008), recebeu o apoio total do G20 e da Assembleia Geral das Nações Unidas.

4 Embora se constitua como um conceito excessivamente lato e impreciso, o trabalho precário corresponde, segundo Guy Caire (1982, p. 135), a um trabalho por tempo determinado, em tempo parcial ou sem contrato. Em contraponto, o trabalho não precário tem as seguintes características: é assalariado, a tempo completo, a tempo indeterminado, com um único vínculo laboral, protegido por lei laboral e/ou negociação coletiva. A precariedade, por seu turno, constitui-se como o produto possível de um trabalho precário. A esse respeito parece-nos ser importante acrescentar um elemento fundamental: o sentido atribuído ao traba- 
lho por parte do indivíduo e a escolha ou a imposição do vínculo precário. Novas formas de relação com o trabalho permitem também a afirmação de trabalhos precários como opção de vida (por exemplo freelancers). A ausência de liberdade de escolha, a ausência de opções (cada vez mais limitadas) e a transformação das pessoas em peças de engrenagens de racionalização (Ritzer, 1996) que se constituem como um elemento profundo na compreensão das sociedades precarizadas atuais e das dinâmicas de desenvolvimento que devem comportar (Sen, 2003).

5 Os principais indicadores de precariedade identificados no estudo foram: tipo de contrato; proteção social na saúde e na velhice; subsídio de desemprego; involuntariedade; não acumulação com um emprego estável (Rosa, 2000).

6 O conceito de informalidade (não tratado aqui em profundidade pela sua complexidade e imprecisão) será considerado no âmbito do presente trabalho como tradutor de todas as situações em que não existe contrato celebrado, correspondendo ou não a trabalho legalizado.

7 O processe pelo qual os princípios do restaurante de fast food tendem a dominar cada vez mais setores da sociedade norte-americana e do restante do mundo (Ritzer, 1996, p. 1).

8 Alan Bryman descreve, sob o conceito de "disneyização" das sociedades atuais, os padrões mercantilizados, consumistas, uniformizados e de certa forma "teatralizados" e "alienantes" que as caracterizam (Bryman, 2004).

9 Restrição associada igualmente a uma mutação dos pressupostos das políticas sociais no sentido da singularização da ação pública e de estratégias de implicação ou ativação dos sujeitos na efetivação do welfare mix.

10 Taxa de desemprego segundo uma nova forma de cálculo do número de desempregados baseada em questionários telefônicos e na utilização de novas tecnologias. No cenário de manutenção do processo de cálculo anterior estima-se que a taxa estaria em 11,4\% (INE, 2011). Entretanto, os últimos números divulgados pelo Eurostat, referentes a abril de 2011 situam a referida taxa em $12,6 \%$.

11 De acordo com os dados do $1^{\circ}$ trimestre de 2011 (INE, 2011), o número de desempregados de longa duração (ou seja, à procura de emprego há doze ou mais meses) correspondia a 53\% (dos quais 29,3\% procuravam emprego há mais de dois anos) da população desempregada total.
12 O valor apresentado, no final de março (2011), pelo Instituto Nacional de Estatística, de 8.6\%, foi corrigido na sequência do pedido de resgate financeiro à União Europeia e ao Fundo Monetário Internacional para $9,1 \%$, devido ao enquadramento de contratos envolvendo parcerias público-privadas (PPP).

13 Trabalho temporário: "se empregador e empregado concordam que o termo do trabalho é determinado por condições objetivas tais como uma data específica, a conclusão de uma tarefa ou o retorno de outro empregado que tenha sido temporariamente substituído (normalmente definidas num contrato de trabalho de duração limitada). São casos típicos: a) pessoas com emprego sazonal; b) pessoas enquadradas por uma agência de emprego e contratadas por uma terceira parte para desempenharem uma tarefa específica (excetuando os casos em que exista um contrato escrito de duração ilimitada); c) pessoas com contratos específicos de formação" (disponível em <http://epp.eurostat.ec.europa.eu/tgm/table.do?tab=table\&init=1\& language $=$ en $\&$ code $=$ tps0073\&plugin $=1>$ ).

14 De acordo com o Relatório da Comissão Europeia "Employment in Europe 2010", são os jovens (15-24 anos) o grupo proporcionalmente mais afetado pela contração do emprego, com o surgimento da crise internacional (decréscimo de 11,4\%). Verificam-se igualmente grandes taxas de emprego temporário nesta população: em 2008, 40\% dos empregados europeus com idades compreendidas entre 15 e 24 anos possuía uma vinculação temporária. Dados divulgados pelo INE (2010) sublinham também que é entre a população jovem portuguesa com formação superior que os contratos a termo e os recibos verdes mais têm crescido (cerca de $129 \%$ na última década).

15 De acordo com dados de 2010 do Observatório das Desigualdades (Portugal), 12\% da população empregada (mais de 500 mil trabalhadores) encontra-se em situação ou em risco de pobreza.

16 Disponível em <http://www.mte.gov.br/rais/2010/ arquivos/Sintese_Brasil.pdf>, acessado em 14.6.2011.

17 Grau de informalidade-Fonte: Instituto Brasileiro de Geografia e Estatística; unidade: (\%). Comentário: Uma das três diferentes definiçóes do grau de informalidade oferecidas no Ipeadata com base na Pesquisa Nacional por Amostra de Domicílios (Pnad) do IBGE, esta taxa corresponde ao resultado da seguinte divisão: (empregados sem carteira + trabalhadores por conta própria)/(trabalhadores protegidos + empregados sem carteira + trabalhadores por conta própria). Elaboração: Disoc/Ipea. Atualizado em 16/2/2011, acessado em 13/6/2011. 


\section{BIBLIOGRAFIA}

ANDERSON, Perry. (1995), "Balanço do neoliberalismo”, in E. Sader (org.), Pós-neoliberalismo, São Paulo, Paz e Terra.

ANTUNES, Ricardo \& POCHMANN, Marcio. (2006), "Dimensões do Desemprego e da Pobreza no Brasil”. Disponível em <http:// www.interfacehs.sp.senac.br/images/artigos/140_pdf.pdf>.

ARENDT, Hannah. (1997), A condição humana. 8. ed. Rio de Janeiro, Forense Universitária.

BALTAR, Paulo \& DEDDECA, Cláudio. (1997), "Mercado de trabalho e informalidade nos anos 90”. Estudos Econômicos, IPE-USP, nº especial: 65-84.

BANCO MUNDIAL. (2001), "O combate à pobreza no Brasil”, in Relatório do Setor de Redução da Pobreza e Manejo Econômico, no 20475 $B R$. Depto. do Brasil.

BECK, Ulrich. (1995), “A reinvenção da política: rumo a uma teoria da modernização reflexiva", in U. Beck, A. Giddense S. Lash, Modernização reflexiva: política, tradição e estética na ordem social moderna, São Paulo, Editora da Unesp.

. (1992), Risk society: towards a new modernity. New Delhi, Sage.

BECK, Ulrich; GIDDENS, A. \& LASH, S. (1995), Modernização reflexiva: política, tradição e estética na ordem social moderna. São Paulo, Editora da Unesp.

BENINI, Édi et al. (orgs.). (2011), Gestão pública e sociedade: fundamentos e politicas de economia solidária. São Paulo, Outras Expressões.

BOURDIEU, Pierre. (1989), O poder simbólico, Lisboa, Difel.

BRAGA, José Carlos de Souza. (1997), "Financeirização global: o padrão sistêmico de riqueza do capitalismo contemporâneo", in Maria da Conceição Tavares e José Luiz Fiori, Poder e dinheiro: uma economia política da globalização, Rio de Janeiro, Vozes.

BRYMAN, A. (2004), The disneyization of society. Londres, Sage.

CASTEL, Robert. (1995), Les métamorphoses de la question sociale: une chronique du salariat. Paris, Librairie Arthème Fayard.
CASTELLS, Manuel. (1999), A sociedade em rede. São Paulo, Paz e Terra.

CAIRE, Guy (1982), "Precarisation des emplois et régulation du marché du travail”. Sociologie $d u$ Travail, 2: 135-158.

CEPAL. (2006), "Panorama social de América Latina”. Relatório, Nações Unidas.

(2007), "Panorama social de América Latina”. Relatório, Nações Unidas.

CEPAL. (2009), "Panorama social de América Latina”. Nações Unidas.

DIEESE. (2010), "Departamento intersindical de estatística e estudos socioeconômicos". Disponível em <http://turandot.dieese.org.br/icv/ TabelaPed?tabela=5>, consultado em 12/3/2010.

ESTANQUE, Elísio. (2005), “Trabalho, desigualdades sociais e sindicalismo". Revista Critica de Ciências Sociais, 71: 113-140.

EUROSTAT, (2001), "Newsrelease euroindicators: seasonally adjusted unemployment rates", april . (2010a), "European Restructuring Monitor", spring. . (2010b), "Base de Dados Labor Force Survey".

GIDDENS, Anthony. (1995), "Risco, confiança, reflexividade", in U. Beck, A. Giddens e S. Lash, Modernização reflexiva: política, tradição e estética na ordem social moderna. São Paulo, Editora da Unesp.

GORZ, André. (1997), Misères du présent: richesse du possible. Paris, Galilée.

GUIMARÃES, Nadya. (2004) "Transições ocupacionais e formas do desemprego em São Paulo e Paris". Comunicação apresentada no Seminário Cebrap. Disponível em <http://www.fflch. usp.br/sociologia/nadya/Transi $\%$ E7\%F5es_ ocupacionais_-SP_e_Paris_CEM_0804.pdf>, consultado em 14/6/2011.

HABERMAS, Jurgen. (1985), "A nova opacidade: a crise do Estado-Providência e o esgotamento das energias utópicas". Separata da Revista de Comunicação e Linguagens, Lisboa, Centro de Estudos de Comunicação e Linguagens, pp. 115-128.

HESPANHA, Pedro (org.). (2007), É o (des) emprego fonte de pobreza? O impacto do desemprego e do mau emprego na pobreza e exclusão social do Distrito de Coimbra. Coimbra, REAPN. 
HESPANHA, Pedro \& CARAPINHEIRO, Graça (orgs). (2001), Risco social e incerteza: pode o Estado-Providência recuar mais? Porto, Afrontamento.

IANNI, Octávio. (1992), A sociedade global. Rio de Janeiro, Civilização Brasileira.

IBGE. PME - Pesquisa Mensal de Emprego. Disponível em <www.ibge.gov.br>, consultado em $12 / 6 / 2011$.

INE. (2010), "Inquérito ao emprego, Portugal". Disponível em <www.pordata.pt>, consultado em 12/3/2010.

KALLEBERG, Arne L. (2009), "O crescimento do trabalho precário: um desafio global". Revista Brasileira de Ciências Sociais, 24 (69): 21-30

KURZ, Robert. (1992), O colapso da modernização. São Paulo, Paz e Terra.

LASH, Scott. (1995). "A reflexividade e seus duplos: estrutura, estética, comunidade", in $\mathrm{U}$. Beck, A. Giddens e S. Lash, Modernização reflexiva: política, tradição e estética na ordem social moderna, São Paulo, Editora da Unesp.

LEITE, Márcia. (2009), "El trabajo y sus reconfiguraciones: las nuevas condiciones de trabajo discutidas a partir de conceptos y realidades". Revista Latinoamericana de Estudios del Trabajo, 21: 7-33.

MARX, Karl. (1980), O capital: critica da economia politica, Rio de Janeiro, Civilização Brasileira.

MÉDA, Dominique. (1999), O Trabalho: um valor em vias de extinção, Lisboa, Fim de Século.

MURTEIRA, Mário. (2004), Economia do conhecimento. Lisboa, Quimera.

NORONHA, Eduardo. (2003), "Informal, ilegal e injusto: percepçōes do mercado de trabalho no Brasil. Revista Brasileira de Ciências Sociais, 18 (53): 111-179.

OIT. (2008). "Declaration on social justice for a fair globalization". Genebra, ILO. (2009), Global Employment Trends 2009. Genebra, ILO.

PIORE, Michael \& SABEL, C. (1984), The second industrial divide. Nova York, Basic Books.

PNUD. (2000), "Superar la pobreza humana". Nova York, Informe del PNUD sobre la pobreza.

PORTES, Alejandro; CASTELLS, Manuel \& BENTON, Lauren (eds.). (1989), The informal economy: studies in advanced and less deve- loped countries. Baltimore/Londres, The John Hopkins University Press.

REICH, Robert. (2001), The future of success: working and living in the new economy. Nova York, Alfred A. Knopt.

RITZER, George. (1996), The McDonaldization of society: an investigation into the changing character of contemporary social life. Thousand Oaks, CA, Pine Forge Press.

RODGERS, Gery \& RODGERS, Janice (orgs.). (1989), Precarious jobs in labour market regulation: the growth of atypical employment in western Europe. Genebra/Bruxelas, International Institute for Labour Studies/Free University of Brussels.

ROSA, Teresa (coord.). (2000), Trabalho precário: perspectivas de superação. Lisboa, Cies.

SADER, Emir (org.). (1995), Pós-neoliberalismo. São Paulo, Paz e Terra.

SANTOS, Boaventura de Sousa. (2001), Globalização: fatalidade ou utopia. Porto, Afrontamento.

SEN, Amartya. (2003), O desenvolvimento como liberdade. Lisboa, Gradiva.

SENNETT, Richard. (2001), A corrosão do carácter: as consequências do trabalho no novo capitalismo. Lisboa, Terramar.

SINGER, Paul Israel. (2002), Introdução à economia solidária. São Paulo: Fundação Perseu Abramo.

SCHNAPPER, Dominique. (1998), Contra o fim do trabalho. Lisboa, Terramar.

SKLAIR, Leslie. (1991), Sociology of the global system. Londres, Harvester Wheatsheaf.

TOKMAN, Victor. (2004), Una voz en el camino: empleo y equidad en America Latina. 40 años de búsqueda. México, Fondo de Cultura Económica.

WALLERSTEIN, Immanuel. (1991), The capitalist world-economy. Cambridge, Cambridge University Press. 


\section{GLOBALIZAÇÃO E RECONFIGURAÇÕES DO MERCADO DE TRABALHO EM PORTUGAL E NO BRASIL}

\section{Adilson Gennari \\ e Cristina Albuquerque}

Palavras-chave: Globalização; Emprego; Precarização; Portugal; Brasil.

No presente artigo procuramos discutir os processos de transformação em curso no mercado de trabalho nos contextos português e brasileiro. Partindo de uma reflexão em torno da globalização e de alguns dos respectivos impactos, fruto de mudanças tecnológicas e da introdução de novas tecnologias de informação, acompanhadas de uma política econômica que privilegia a desregulamentação e a flexibilização das relações laborais, discutimos tendências de precarização do emprego nos dois países. Ancoramos, assim, nossa reflexão no pressuposto de que a precariedade do emprego, que afeta hoje todas as classes etárias e profissionais, deixou de ser um mero fenômeno conjuntural e periférico.

\section{GLOBALIZATION AND LABOR MARKET RECONFIGURATIONS IN PORTUGAL AND BRAZIL}

\author{
Adilson Gennari \\ and Cristina Albuquerque
}

Keywords: Globalization; Employment precariousness; Portugal; Brazil.

the article discusses the processes of transformation that are underway in the contexts of Portuguese and Brazilian labor markets. Starting with a reflection on globalization and some of its impacts - resulting from technological changes and the introduction of new information technologies, accompanied by an economic policy that favors deregulation and flexibility of labor relations -, it analyses some trends regarding precarious employment in both countries. The discussion is grounded on the assumption that job precariousness, which currently affects all age and professional groups, is not anymore a mere cyclical and peripheral phenomenon.

\section{MONDIALISATION ET RECONFIGURATIONS DU MARCHÉ DE TRAVAIL AU PORTUGAL ET AU BRÉSIL}

\author{
Adilson Gennari \\ et Cristina Albuquerque
}

Mots-clés: Mondialisation; Emploi; Précarité; Portugal; Brésil.

Nous nous proposons, dans cet article, de discuter les processus de transformation qui sont en cours dans le marché du travail au Brésil et au Portugal. À partir d'une réflexion sur la mondialisation et de certains de ses impacts, issus des changements technologiques et de l'introduction de nouvelles technologies de l'information, suivis d'une politique économique qui privilégie la dérèglementation et la flexibilisation des relations du travail, nous discutons les tendances de précarité du travail dans les deux pays. Notre réflexion est ancrée dans le présupposé suivant lequel la précarité de l'emploi - qui affecte de nos jours toutes les classes professionnelles et d'âge n'est plus un phénomène simplement conjoncturel et périphérique. 